\title{
Degradation and mineralization of violet-3B dye using C-N-codoped $\mathrm{TiO}_{2}$ photocatalyst
}

\author{
Reza Audina Putri ${ }^{1}$, Safni Safni ${ }^{1^{\dagger}}$, Novesar Jamarun ${ }^{2}$, Upita Septiani ${ }^{2}$, Moon-Kyung Kim ${ }^{3}$, \\ Kyung-Duk Zoh ${ }^{3}$ \\ ${ }^{1}$ Laboratory of Applied Analytical-Chemistry, Faculty of Mathematic and Natural Sciences, Andalas University, Padang 25163, Indonesia \\ ${ }^{2}$ Laboratory of Material, Faculty of Mathematic and Natural Sciences, Andalas University, Padang 25163, Indonesia \\ ${ }^{3}$ Institute of Health and Environment, Seoul National University, Seoul 08826, Korea
}

\begin{abstract}
The present study investigated the photodegradation of synthetic organic dye; violet-3B, without and with the addition of $\mathrm{C}-\mathrm{N}-\mathrm{codoped}$ TiO $\mathrm{O}_{2}$ catalyst using a visible halogen-lamp as a light source. The catalyst was synthesized by using a peroxo sol-gel method with free-organic solvent. The effects of initial dye concentration, catalyst dosage, and $\mathrm{pH}$ solution on the photodegradation of violet-3B were examined. The efficiency of the photodegradation process for violet-3B dye was higher at neutral to less acidic $\mathrm{pH}$. The kinetics reaction rate of photodegradation of violet-3B dye with the addition of $\mathrm{C}-\mathrm{N}$-codoped $\mathrm{TiO}_{2}$ followed pseudo-first order kinetics represented by the Langmuir-Hinshelwood model, and increasing the initial concentration of dyes decreased rate constants of photodegradation. Photodegradation of $5 \mathrm{mg} \mathrm{L}^{-1}$ violet-3B dye achieved $96 \%$ color removal within $240 \mathrm{~min}$ of irradiation in the presence of C-N-codoped $\mathrm{TiO}_{2}$ catalyst, and approximately $44 \%$ TOC was removed as a result of the mineralization.
\end{abstract}

Keywords: C-N-codoped $\mathrm{TiO}_{2}$, HPLC, Kinetics, TOC, Vat-dye, Visible halogen-lamp

\section{Introduction}

Violet-3B, a group of anthraquinones vat dyes, is widely used for fabric dyeings such as cotton, viscose, and silk [1]. This dye can be produced during coloring and dyeing processes of fabric and become a pollutant when it is discharged into river water without an effective treatment. The wastewater effluent from dyeing industry can contain a large amount of azoic, anthraquinonic, and heteropolyaromatic dyes [2-4] which are hazardous to the aquatic life because of its toxicity and carcinogenicity [5-6]. Besides, the color of dyes can damage the aesthetic aspect of water and reduces light penetration causing the inhibition of photosynthesis process of the aquatic organism [7]. These wastewater effluents from dyeing industry can be a serious environmental pollution if there is no treatment before releasing to the waterways [8]. Therefore, many researchers are looking for appropriate treatments in order to remove these dyes.

The conventional technologies, such as adsorption [9-10], coagu- lation/flocculation [11] and conventional chemical oxidation [12] have been used for the removal of dyes. However, these techniques are ineffective because they are non-destructive and produce secondary pollution requiring further treatment for their safe disposal [13]. Therefore, the alternative treatment which can solve the problem in conventional technologies is required. Advanced oxidation processes (AOPs) based on the generation of highly reactive hydroxyl radicals $(\cdot \mathrm{OH})$ to reduce more number of recalcitrant pollutants [14]. This process can reduce pollutant into environment-friendly products without the generation of waste.

Heterogeneous photocatalysis is one of the best AOP processes to degrade organic pollutants [15]. The key to the photocatalysis process is the combination of semiconductor photocatalyst and light sources [16]. Titanium dioxide $\left(\mathrm{TiO}_{2}\right)$ is the most promising and widely used as a photocatalyst in wastewater treatment among the various semiconductors. Titania $\left(\mathrm{TiO}_{2}\right)$ has strong catalytic activity, its low cost, and photo-stability [17]. As a photocatalyst, $\mathrm{TiO}_{2}$ has its own deficiency because of its large bandgap energy
This is an Open Access article distributed under the terms of the Creative Commons Attribution Non-Commercial License (http://creativecommons.org/licenses/by-nc/3.0/) which permits unrestricted non-commercial use, distribution, and reproduction in any medium, provided the original work is properly cited.

Copyright (C) 2020 Korean Society of Environmental Engineers
Received May 8, 2019 Accepted August 2, 2019

${ }^{\dagger}$ Corresponding author

Email: safni@sci.unand.ac.id

Tel: +62 813-7428-2673

ORCID: 0000-0003-0307-5211 
( $\sim 3.2 \mathrm{eV}$ for the anatase phase) [18]. Thus, it should be activated and applied by UV light only. In a consequence, modification of $\mathrm{TiO}_{2}$ to enhance photoactivity under visible light has been developed. The simplest and most potential approach to modify $\mathrm{TiO}_{2}$ seems to be doped with non-metal elements [19], transition metal elements [20], and the combination of both elements [21-22].

In our previous researches, $\mathrm{C}-\mathrm{N}$-codoped $\mathrm{TiO}_{2}$ has been applied to degrade other vat dyes such as orange-F3R [23] and yellow-GCN [24], but the kinetics of photodegradation reaction has not been studied. Moreover, to our best knowledge, there have been no researches related to the treatment of violet-3B dye using photodegradation in the presence of $\mathrm{C}-\mathrm{N}$-codoped $\mathrm{TiO}_{2}$. Thus, the purpose of this research is to examine the kinetics reaction of violet-3B dye photodegradation in the presence of C-N-codoped $\mathrm{TiO}_{2}$ catalyst. To achieve color removal, various parameters which affect the photodegradation process such as catalyst dosage, initial dye concentration, $\mathrm{pH}$ of the solution, and adsorption on C-N-codoped $\mathrm{TiO}_{2}$ are investigated. Finally, the mineralization of dyes during the degradation is assessed by the Total Organic Carbon (TOC) analysis.

\section{Experimental Section}

\subsection{Chemicals}

Violet-3B dye (Vat Violet 9) (C.I. number 60005, CAS number 1324-17-0) was purchased from indiamart (India) and used in this research without further purification. The molecular formula of Violet-3B is $\mathrm{C}_{35} \mathrm{H}_{19} \mathrm{BrO}_{2}$, the molecular weight is $551.43 \mathrm{~g} \mathrm{~mol}^{-1}$. $100 \mathrm{mg} \mathrm{L}^{-1}$ of violet-3B dye stock solution was prepared by dissolving $100 \mathrm{mg}$ of violet-3B dye powder into $1 \mathrm{~L}$ of deionized water. C-N-codoped $\mathrm{TiO}_{2}$ was synthesized in the laboratory and prepared using sol-gel organic-free preparation [25, 26]. Graphite carbon-powder (10 wt \%) was sonicated for $1 \mathrm{~h}$ in distilled water then titanium (IV) chloride (Merck) was added to carbon suspension. The $\mathrm{pH}$ of the solution was adjusted to 10 by dropwise addition of ammonia solution (Merck, 25\%). The carbon-nitrogen-aqueous peroxotitanate solution (CN-PTA) was obtained after stirring for $24 \mathrm{~h}$. The solution was centrifuged and washed thoroughly with distilled water then the precipitates were solved with distilled water and hydrogen peroxide (Merck, 30\%). After stirring for $4 \mathrm{~h}$ the solvents were vapored by using rotary evaporator then the precipitates were calcined in the air at $500^{\circ} \mathrm{C}$ for $1 \mathrm{~h}$.

\subsection{Photodegradation Process of Violet-3B Dye}

All experiments were performed under atmospheric pressure at $293 \mathrm{~K}$ inside black irradiation box. Visible halogen-lamp (500 W, Phillips) was used as light-sources for photodegradation process, and the distance to dye solution was $10 \mathrm{~cm}$. The initial concentration of $5 \mathrm{mg} \mathrm{L}^{-1}$ violet-3B dye was used in every experiment except for investigating the effect of the initial dye concentration. The dosage of $\mathrm{C}-\mathrm{N}$-codoped $\mathrm{TiO}_{2}$ was $0.3 \mathrm{~g} \mathrm{~L}^{-1}$ for every photocatalysis and adsorption experiment. The initial $\mathrm{pH}$ of the reaction solution was the natural $\mathrm{pH}$ of violet-3B dye solution ( $\mathrm{pH}$ 5.6) except for investigating the effect of $\mathrm{pH}$. The degradation products were analyzed by HPLC system.

\subsection{Sample Analysis}

All liquids samples were centrifuged (1,700 rpm for $10 \mathrm{~min}$ ) to separate $\mathrm{C}-\mathrm{N}$-codoped $\mathrm{TiO}_{2}$ particles prior to analysis. The violet-3B dye was analyzed by high performance liquid chromatography using a Summit ${ }^{\mathrm{TM}}$ HPLC system (Dionex, USA), the injection volume was $500 \mu \mathrm{L}$. An ODS-Hypersyl (Thermo Scientific) column (150 $\mathrm{mm} \times 4.6 \mathrm{~mm}$ ) with $5 \mathrm{~mm}$ particle size was used. The mixture of deionized water and methanol (70:30, v/v\%) was used as mobile phase, and the flow rate was $0.8 \mathrm{~mL} \mathrm{~min}^{-1}$. The detector was performed with visible lamp and was set at $540 \mathrm{~nm}$. Mineralization analysis of the violet-dye samples during photodegradation was performed on a Shimadzu TOC analyzer (Shimadzu, Japan). The degradation percentage of dye from solution at different time interval and condition is calculated by Eq. (1);

$$
\text { \%removal }=\frac{C_{t}}{C_{o}} \times 100 \%
$$

where $C_{o}$ is the initial concentration of violet-3B dyes and $C_{t}$ is the concentration of violet-3B dyes after photolysis process at different condition.

\section{Results and Discussion}

\subsection{Degrdation of Violet-3B Dye}

HPLC-system is used at wavelength $540 \mathrm{~nm}$ to calculate the change of violet-3B dye concentration during the photodegradation process. Fig. 1 shows the chromatogram of violet-3B dye with a single peak obtained. The peak of violet-3B appears at $0.78 \mathrm{~min}$ of retention time. However, after photolysis, in the presence of $\mathrm{C}-\mathrm{N}$-codoped $\mathrm{TiO}_{2}$ catalyst, the intensity of the peak decreased significantly showing high removal of violet-3B dye.

\subsection{Effect of Catalyst Dosage}

The effect of $\mathrm{C}-\mathrm{N}$-codoped $\mathrm{TiO}_{2}$ dosage on the degradation of violet-3B dye was investigated by varying the concentration of $\mathrm{TiO}_{2}$ catalyst from 0.05 to $1.2 \mathrm{~g} \mathrm{~L}^{-1}$ in the photolysis process for 180 $\mathrm{min}$. The removal percentage of violet dye shows that, as the amount of catalyst increase up to $0.3 \mathrm{~g} \mathrm{~L}^{-1}$, with the removal percentage of violet-3B dye, increased up to $83 \%$. The increasing amount of catalyst produces the number of sites available for photons absorption thus more hydroxyl radical $(\bullet \mathrm{OH})$ is formed to degrade the organic molecule of violet-3B dye [27, 28]. However, the addition of $\mathrm{C}-\mathrm{N}$-codoped $\mathrm{TiO}_{2}$ dosage higher than $0.3 \mathrm{~g} \mathrm{~L}^{-1}$ caused the decrease in removal percentage of violet-3B dye to $71 \%$. This phenomenon could be due to the turbidity of dye solution resulting in less light penetration and blocking the light scattering [27, 29]. Hence, the optimum dosage of $\mathrm{C}-\mathrm{N}$-codoped $\mathrm{TiO}_{2}$ catalyst used in the violet-3B dye photodegradation is $0.3 \mathrm{~g} \mathrm{~L}^{-1}$.

\subsection{Effect of $\mathrm{C}-\mathrm{N}$-codoped $\mathrm{TiO}_{2}$ in the Photolysis}

To confirm the role of $\mathrm{C}-\mathrm{N}$-codoped $\mathrm{TiO}_{2}$ in the photodegradation reaction, three sets of experiment were performed to compare violet-3B dye degradation rates with and without a catalyst. The first 

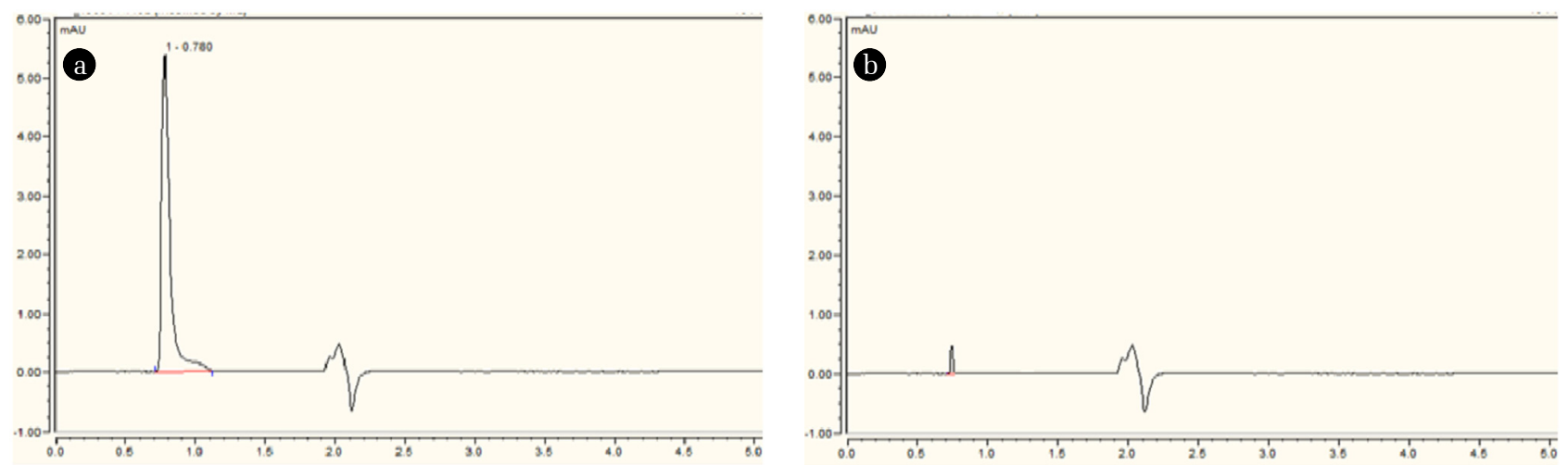

Fig. 1. Chromatogram of $5 \mathrm{mg} \mathrm{L}^{-1}$ violet-3B dye. (a) Before degradation and (b) After degradation for 300 min by the addition of $\mathrm{C}-\mathrm{N}$-codoped $\mathrm{TiO}_{2}$.

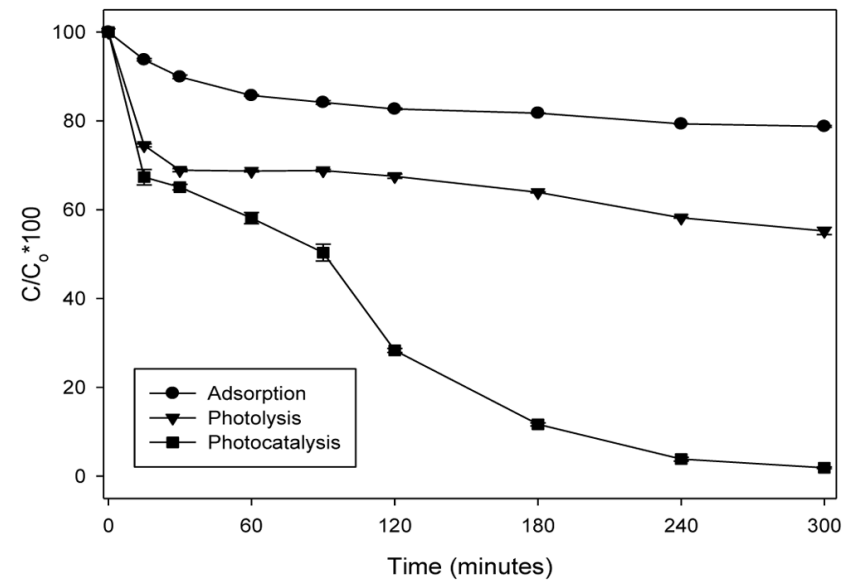

Fig. 2. Photodegradation of $5 \mathrm{mg} \mathrm{L}^{-1}$ violet dyes under photocatalysis, photolysis and adsorption condition $(\mathrm{pH}=5.6, \mathrm{C}-\mathrm{N}$-codoped $\mathrm{TiO}_{2}=0 \mathrm{~g} \mathrm{~L}^{-1}$ in photolysis, $0.3 \mathrm{~g} \mathrm{~L}^{-1}$ in photocatalysis and adsorption) $(\mathrm{n}=3)$.

set was performed by exposing violet-3B dye $\left(5 \mathrm{mg} \mathrm{L}^{-1}\right)$ with the addition of $0.3 \mathrm{~g} \mathrm{~L}^{-1} \mathrm{C}-\mathrm{N}$-codoped $\mathrm{TiO}_{2}$ under visible-light irradiation (photocatalysis condition). The second set was performed by exposing violet-3B dye to visible light without $\mathrm{C}-\mathrm{N}$-codoped $\mathrm{TiO}_{2}$ catalyst (photolysis condition). Then, the third set was adsorption condition by exposing violet-3B to C-N-codoped $\mathrm{TiO}_{2}$ without visible-light irradiation. The results of violet-3B dye removal are shown in Fig. 2.

The experiment with $\mathrm{C}-\mathrm{N}$-codoped $\mathrm{TiO}_{2}$ showed that the small amount of violet-3B dye (about 20\%) was adsorbed on the C-N-codoped $\mathrm{TiO}_{2}$ surface after $300 \mathrm{~min}$. The adsorption phenomenon might be caused by carbon dopant in $\mathrm{TiO}_{2}$ crystal. During photolysis condition, about $45 \%$ of the violet dye was removed after 300 min of irradiation. High irradiation energy from visible lamp could degrade the molecules of violet-3B dye. Approximately, $98 \%$ of the violet dye was removed by the addition of C-N-codoped $\mathrm{TiO}_{2}$ in the photodegradation process.

Higher removal percentage of violet dyes was achieved during photocatalysis condition due to that more hydroxyl radical $(\cdot \mathrm{OH})$ radicals can react with violet-3B dye molecules and achieve mineral- ization process. The $\cdot \mathrm{OH}$ radical was produced by the reaction between electron vacancy or hole site $\left(h^{+}\right)$of $\mathrm{TiO}_{2}$ with water. Since carbon and nitrogen dopant was inserted to $\mathrm{TiO}_{2}$, visible light could be absorbed by $\mathrm{TiO}_{2}$ and causing the excitation process of the electron from valence band to conduction band [30]. The reaction was shown at Eq. (2) and (3) [17];

$$
\begin{gathered}
\mathrm{TiO}_{2}+\text { visible-light } \rightarrow \\
\mathrm{TiO}_{2}\left(\mathrm{e}_{\mathrm{cb}}^{-}+\mathrm{h}_{\mathrm{vb}}{ }^{+}\right. \text {) (electron-hole generation) } \\
\mathrm{TiO}_{2}\left(\mathrm{~h}_{\mathrm{vb}}{ }^{+}\right)+\mathrm{H}_{2} \mathrm{O} \rightarrow \mathrm{TiO}_{2}+\mathrm{H}^{+}+\cdot \mathrm{OH}
\end{gathered}
$$

while the excited electron in the conductance band can produce $\bullet \mathrm{OH}$ radical by reacting with oxygen shown in Eq. (4) to (8) [17, 31];

$$
\begin{aligned}
& \mathrm{TiO}_{2}\left(\mathrm{e}_{\mathrm{cb}}{ }^{-}\right)+\mathrm{O}_{2} \rightarrow \mathrm{TiO}_{2}+\mathrm{O}_{2}{ }^{\circ} \\
& \mathrm{O}_{2}^{*-}+\mathrm{H}^{+} \rightarrow \mathrm{HO}_{2} \cdot \\
& 2 \mathrm{O}_{2}{ }^{--}+2 \mathrm{H}^{+} \rightarrow \mathrm{O}_{2}+\mathrm{H}_{2} \mathrm{O}_{2} \\
& \mathrm{H}_{2} \mathrm{O}_{2}+\mathrm{TiO}_{2}\left(\mathrm{e}_{\mathrm{cb}}{ }^{-}\right) \rightarrow \cdot \mathrm{OH}+\mathrm{OH}^{-}+\mathrm{TiO}_{2} \\
& \mathrm{HO}_{2} \bullet+\mathrm{H}^{+}+\mathrm{TiO}_{2}\left(\mathrm{e}_{\mathrm{cb}}{ }^{-}\right) \rightarrow \bullet \mathrm{OH}+\mathrm{OH}^{-}+\mathrm{TiO}_{2}
\end{aligned}
$$

\subsection{Effect of Initial Dye Concentration}

Various violet-3B dye concentrations in the range 5 to $30 \mathrm{mg} \mathrm{L}^{-1}$ were tested to investigate the effect of initial dye concentration during photocatalysis condition for $420 \mathrm{~min}$ in the presence of C-N-codoped $\mathrm{TiO}_{2}$ catalyst. The results are shown in Fig. 3. It was found that the low concentration of violet-3B dye was favorable for the photodegradation process.

By increasing the initial concentration of dye lead to a decrease in violet-3B degradation rate. This effect can be explained by the increase in the dye concentration, caused the decrease in the light penetration that reaches the organic molecule of violet-3B dye due to the declining transparency of the solution into a more concentrated solution [27-28]. Thus, the time for complete degradation of violet-3B dye would be longer for higher initial violet-3B concentrations [29, 32]. The result of the effect of initial dye concentration showing in Fig. 3 indicates that violet-3B degradation kinetics are not simple first-order but pseudo-first-order. 


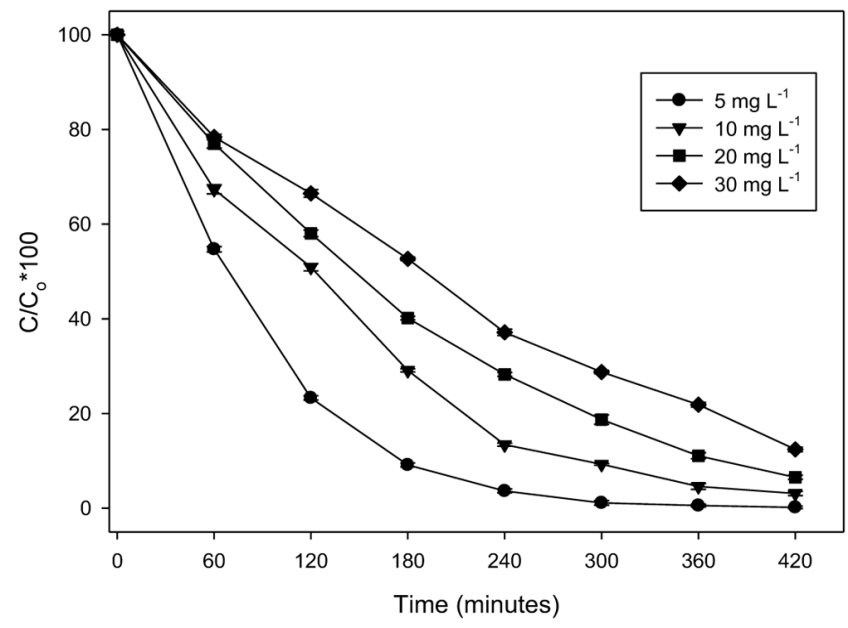

Fig. 3. Effect of initial dye concentration on removal efficiency under photocatalysis condition $\left(\mathrm{pH}=5.6, \mathrm{C}-\mathrm{N}\right.$-codoped $\mathrm{TiO}_{2}=0.3 \mathrm{~g}$ $\mathrm{L}^{-1}, \mathrm{n}=3$ ).

\subsection{Reaction Kinetics}

Photodegradation reaction using C-N-codoped $\mathrm{TiO}_{2}$ as a catalyst is known to be a heterogeneous reaction between violet-3B dye and $\mathrm{TiO}_{2}$, and the $\cdot \mathrm{OH}$ radicals produced from the reaction bewteen $\mathrm{TiO}_{2}$ and $\mathrm{H}_{2} \mathrm{O}$ is the main key in the oxidation reaction of dye degradation. The Langmuir-Hinshelwood kinetic model can be applied for heterogenous photodegradation in the correlation between the initial degradation rate and the initial concentration of dyes [33], in this model, the reaction rate for second-order catalyst surface decomposition of violet-3B dye is expressed as follows;

$$
\text { rate }=-\frac{\mathrm{d}[\text { dye }]}{\mathrm{dt}}=\mathrm{k}_{\mathrm{c}} \frac{\mathrm{K}_{\mathrm{dye}}[\text { dye }]}{1+\mathrm{K}_{\mathrm{dy}}[\mathrm{dye}]_{\mathrm{o}}}
$$

where [dye] is the concentration of violet-3B dye at time $\mathrm{t}$ and $[d y e]_{\mathrm{o}}$ is the initial concentration of violet-3B dye, $k_{c}$ is the second-order rate constant, $K_{d y e}$ is the equilibrium adsorption constant of dye onto the surface of $\mathrm{C}-\mathrm{N}$-codoped $\mathrm{TiO}_{2}$. In this research since the initial concentrations of violet-3B dye used were relatively low, based on the Eq. (9) the kinetics data were modeled using pseudo-first-order;

$$
-\mathrm{d} \frac{[\text { dye }]}{\mathrm{dt}}=\mathrm{k}_{\mathrm{obs}}[\text { dye }]=\mathrm{k}_{\mathrm{c}} \frac{\mathrm{k}_{\mathrm{dye}}}{1+\mathrm{k}_{\mathrm{dye}}[\text { dye }]_{0}}[\text { dye }]
$$

where $k_{\text {obs }}$ is the observed pseudo-first-order rate constant for the photodegradation oxidation of violet-3B dye using C-N-codoped $\mathrm{TiO}_{2}$ as a catalyst. The integration of Eq. (10) results in Eq (10);

$$
\ln \left(\frac{[\text { dye }]}{\left[\text { dye }_{0}\right.}\right)=-\mathrm{kt}
$$

Based on Eq. (11), a plot of $\ln \left(\left[\right.\right.$ dye $_{\mathrm{o}} /[$ dye] $]$ versus irradiation time represents a straight line showing in Fig. 4 and Table 1. The relationship between $k_{o b s}$ and the initial concentration of violet-3B dye $[d y e]_{o}$ from Eq. (11) can be expressed by;

$$
\frac{1}{\mathrm{k}_{\mathrm{obs}}}=\frac{1}{\mathrm{k}_{\mathrm{c}} \mathrm{K}_{\mathrm{dye}}}+\frac{\left[\mathrm{dye}_{\mathrm{o}}\right.}{\mathrm{k}_{\mathrm{c}}}(12)
$$

The linear expression was obtained by plotting the proportion of degradation rate $\left(1 / \mathrm{k}_{\mathrm{obs}}\right)$ versus the initial concentration of violet-3B dye, the curve is shown in Fig. 4. By fitting the Eq. (12), the values of the adsorption equilibrium constant $\left(K_{d y e}\right)$ and the second-order constant $\left(k_{c}\right)$ were obtained, and the value found to be $K_{\text {dye }}=0.129 \mathrm{~L} \mathrm{mg}^{-1}$ and $k_{c}=0.18 \mathrm{mg} \mathrm{L}^{-1} \mathrm{~min}^{-1}\left(\mathrm{R}^{2}=0.987\right)$, respectively.

Table 1. Effect of Initial Concentration to Rate Constant of Violet-3B Dye Photodegradation

\begin{tabular}{ccccc}
\hline $\begin{array}{c}\text { Initial dye } \\
\left(\mathbf{m g ~ L}^{-1}\right)\end{array}$ & $\begin{array}{c}\mathbf{k}_{\text {obs }} \\
\left(\mathbf{m i n}^{-1}\right)\end{array}$ & $\begin{array}{c}\mathbf{1} / \mathbf{k}_{\text {obs }} \\
(\mathbf{m i n})\end{array}$ & $\begin{array}{c}\mathbf{t}_{\mathbf{1} / \mathbf{2}} \\
(\mathbf{m i n})\end{array}$ & $\mathbf{R}^{\mathbf{2}}$ \\
\hline 5 & 0.0152 & 65.79 & 45.60 & 0.996 \\
10 & 0.0092 & 108.69 & 75.34 & 0.984 \\
20 & 0.0067 & 149.25 & 103.45 & 0.975 \\
30 & 0.0047 & 212.76 & 147.48 & 0.976 \\
\hline
\end{tabular}

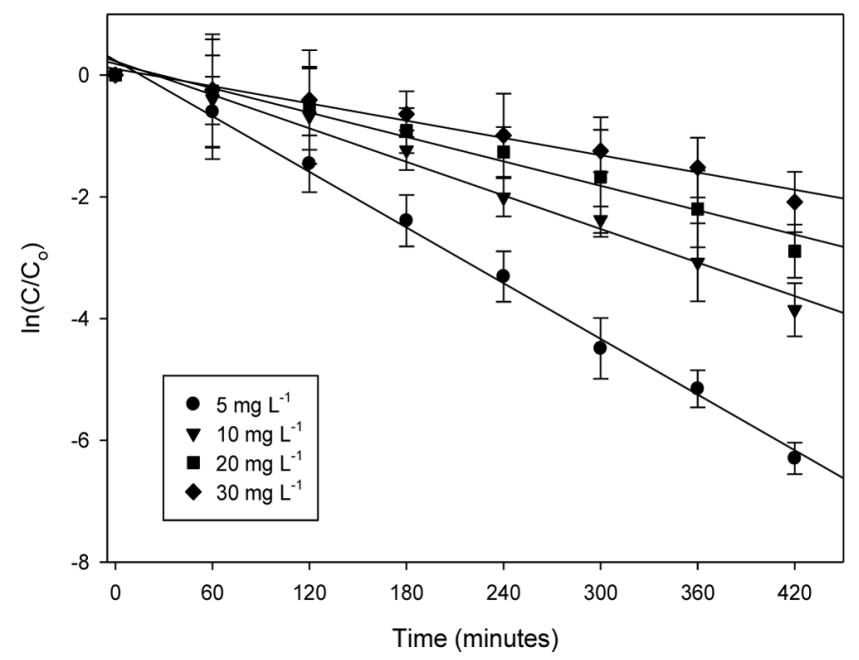

Fig. 4. Photodegradation kinetics model in various concentration of violet-3B dye in the present of catalyst $(\mathrm{pH}=5.6, \mathrm{C}-\mathrm{N}$-codoped $\mathrm{TiO}_{2}=0.3 \mathrm{~g} \mathrm{~L}^{-1}, \mathrm{n}=3$ ).

The pseudo-first-order rate constant $\left(\mathrm{k}_{\mathrm{obs}}\right)$, half-time $\left(\mathrm{t}_{1 / 2}\right)$, and the correlation coefficients $\left(\mathrm{R}^{2}\right)$ for photodegradation of violet-3B dye at different initial concentration, experimental conditions: the mass of C-N-codoped $\mathrm{TiO}_{2}=0.3 \mathrm{~g} \mathrm{~L}^{-1}$, natural $\mathrm{pH} ; \mathrm{n}=3$

\subsection{Effect of Initial $\mathrm{pH}$}

To investigate the effect of initial $\mathrm{pH}$ on degradation of violet-3B dye, the experiments were conducted by changing the $\mathrm{pH}$ of dye solution from 3 to 10 . The concentration of violet-3B dye was kept constant at $5 \mathrm{mg} \mathrm{L}^{-1}$ and the mass of $\mathrm{C}-\mathrm{N}$-codoped $\mathrm{TiO}_{2}$ catalyst is $0.3 \mathrm{~g} \mathrm{~L}^{-1}$. Fig. 5 shows the results of degradation efficiency for every $\mathrm{pH}$ condition and Table 2 shows the pseudo-first-order rate constant. The order of degradation efficiency follows $\mathrm{pH} 5>\mathrm{pH}$ $7>\mathrm{pH} 3>\mathrm{pH}$ 10. It is known that $\mathrm{TiO}_{2}$ has an amphoteric 


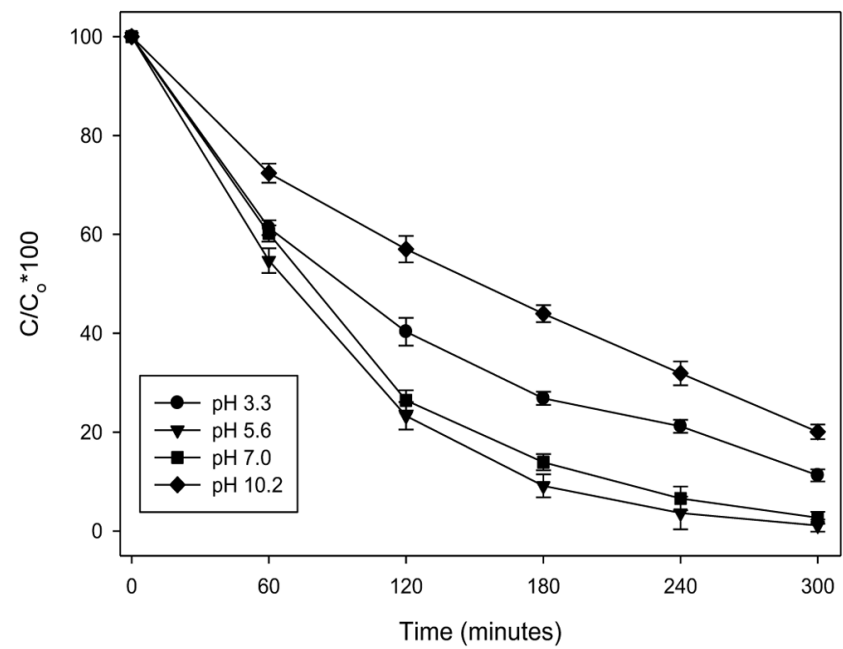

Fig. 5. Effect of pH solution on degradation efficiency, under photocatalysis condition(violet-3B dye $=5 \mathrm{mg} \mathrm{L}^{-1}, \mathrm{C}-\mathrm{N}$-codoped $\mathrm{TiO}_{2}$ $=0.3 \mathrm{~g} \mathrm{~L}^{-1}, \mathrm{n}=3$ ).

Table 2. Effect of Initial $\mathrm{pH}$ to Rate Constant of Violet-3B Dye Photodegradation

\begin{tabular}{cccc}
\hline $\mathbf{p H}$ & $\begin{array}{c}\mathbf{k}_{\mathbf{o b s}} \\
\left(\mathbf{m i n}^{-\mathbf{1}}\right)\end{array}$ & $\begin{array}{c}\mathbf{t}_{\mathbf{1} / \mathbf{2}} \\
(\mathbf{m i n})\end{array}$ & $\mathbf{R}^{\mathbf{2}}$ \\
\hline 3.3 & 0.0069 & 100.46 & 0.989 \\
5.6 & 0.015 & 46.21 & 0.991 \\
7.0 & 0.012 & 57.76 & 0.995 \\
10.2 & 0.0051 & 135.91 & 0.967 \\
\hline
\end{tabular}

character in aqueous solution. The point of zero charges $\left(\mathrm{p}_{\mathrm{zc}}\right)$ of C-N-codoped $\mathrm{TiO}_{2}$ was found at $\mathrm{pH} 5.29$ [34]. Since the $\mathrm{pH}$ condition of dye solution near the $p_{z c}$ can be favorable to adsorb the molecule of violet-3B and therefore the highest degradation percentage was achieved at $\mathrm{pH}$ 5.6. While at neutral $\mathrm{pH}$, the efficiency of $\mathrm{TiO}_{2}$ catalyst in photodegradation was not changed [35], however further increase in $\mathrm{pH}$ will decrease the degradation efficiency due to the electrostatic repulsion between negative charge of catalyst surface ( $\mathrm{TiO}^{-}$) at alkaline condition [36] and the $\mathrm{OH}^{-}$species in photocatalytic mechanism [37]. Therefore, the optimum $\mathrm{pH}$ condition for photodegradation of violet-3B using C-N-codoped $\mathrm{TiO}_{2}$ was at circumneutral $\mathrm{pH}$ (between 5 and 7).

The pseudo-first-order rate constant $\left(\mathrm{k}_{\mathrm{obs}}\right)$, half-time $\left(\mathrm{t}_{1 / 2}\right)$, and the correlation coefficients $\left(\mathrm{R}^{2}\right)$ for photodegradation of violet-3B dye at different $\mathrm{pH}$ (experiment conditions: dye $=5 \mathrm{mg} \mathrm{L}^{-1}$, C-N-codoped $\mathrm{TiO}_{2}=0.3 \mathrm{~g} \mathrm{~L}^{-1}$ )

\subsection{Mineralization}

To confirm the mineralization, the photodegradation of violet-3B using C-N-codoped $\mathrm{TiO}_{2}$ catalyst reaction were carried out up to $300 \mathrm{~min}$ and the irradiated samples were analyzed by TOC analyzer. Fig. 6 shows the comparison of removal efficiency of violet-3B dye and TOC reduction in photolysis with the addition of C-N-COdoped $\mathrm{TiO}_{2}$ catalyst. The results showed $45 \%$ reduction in TOC under irradiated of visible-light for $300 \mathrm{~min}$. This result indicates

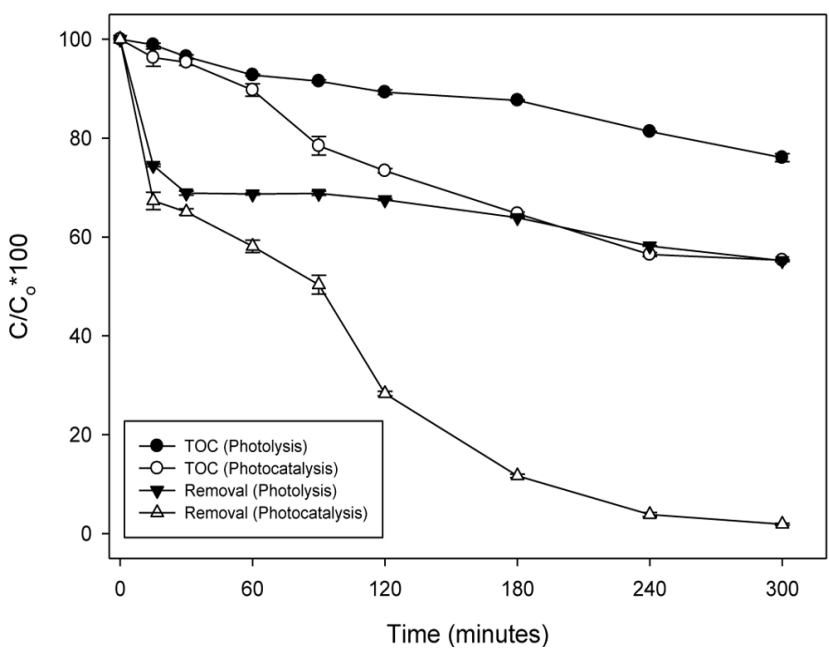

Fig. 6. TOC reduction and removal efficiency comparison for photodegradation of violet-3B dye (experimental conditions: dye $=$ $5 \mathrm{mg} \mathrm{L}^{-1}$, mass of C-N-codoped $\mathrm{TiO}_{2}=0.3 \mathrm{~g} \mathrm{~L}^{-1}$, natural $\mathrm{pH}, \mathrm{n}=3$ ).

that, although $98 \%$ of the color removal was achieved within 300 min with the irradiation of visible light, the organic compound of the violet-3B is not completely mineralized.

\section{Conclusions}

The experimental results of this study show that photodegradation using $\mathrm{C}-\mathrm{N}$-codoped $\mathrm{TiO}_{2}$ as a catalyst could be applied to the treatment of violet-3B dye wastewater. The combination between C-N-codoped $\mathrm{TiO}_{2}$ and visible light in photodegradation showed more efficient to degrade violet-3B dye than visible light and catalyst alone. For 300 min photodegradation process, $5 \mathrm{mg} \mathrm{L}^{-1}$ violet-3B dye was adsorbed as much $21 \%$ onto $0.3 \mathrm{~g} \mathrm{~L}^{-1} \mathrm{C}-\mathrm{N}$-codoped $\mathrm{TiO}_{2}$ surface, $45 \%$ of color removal was achieved by irradiation of visible-light only and increased to $98 \%$ by photocatalysis. The photodegradation of violet-3B using C-N-codoped $\mathrm{TiO}_{2}$ was fitted to the Langmuir-Hinshelwood model and obeyed the pseudo-first-order kinetics. In the mineralization study, the photodegradation process in the presence of $\mathrm{C}-\mathrm{N}$-codoped $\mathrm{TiO}_{2}$ achieved an approximately $45 \%$ TOC removal. The mechanism of violet-3B dye photodegradation is still in studying.

\section{Acknowledgment}

The authors would like to acknowledge the support of the Ministry of Research, Technology and Higher Education of the Republic of Indonesia (RISTEKDIKTI). This research was fully supported by the master program of education leading to doctoral degree for excellent graduates (PMDSU) (Grant No. 050 / SP2H / LT / DRPM / 2018).

\section{References}

1. Muhammad M, Abher R, Assad F, Munir A, Amin S. 
Environment friendly finishing of sulphur, vat, direct and reactive dyed cotton fabric. J. Clean. Prod. 2013;53:341-347.

2. Balan DSL, Monteiro RTR. Decolorization of textile Indigo dye by ligninolytic fungi. J. Biotechnol. 2001;89:141-145.

3. Eleana K, Kyriakos B, Alexis L, Christos K. The mechanism of azo-dyes adsorption on the titanium dioxide surface and their photocatalytic degradation over samples with various anatase/rutile ratio. Catal. Today 2014;30:8-16.

4. Prakash K, Narayana J, Arthoba NY. Degradation of textile dye C.I. Vat Black 27 by electrochemical method by using carbon electrodes. J. Environ. Chem. Eng. 2013;1:975-980.

5. Santhi P, Moses JJ. Study on different reducing agents for effective vat dyeing on cotton fabric. Indian J. Fibre Text. Res. 2010;35:349-352.

6. Gisela de Aragao U, Harold SF, Sarah HW, et al. The contribution of azo dyes to the mutagenic activity of the Cristais River. Chromosphere 2005;60:55-64.

7. Carmen Z, Daniela S. Textile organic dyes-characteristics, polluting effects and seperation/elimination procedures from industrial effluents-acritical overview. In: Organic Pollutan Ten Years After the Stockhim Conevntion - Environmental and Analytical Update InTech Croatia; 2012. p. 55-86.

8. Nese T, Nuket S, Ismail T. Pollutants of textile industry wastewater and assesement of its discharge limits by water quality standards. Turk. J. Fish. Aqua. Sci. 2007;7:97-103.

9. Chaari I, Jamoussi F. Application of activated carbon for vat dye removal from aqueous solution. J. Appl. Sci. Environ. Sanit. 2011;6:247-256.

10. Santhi T, Manonmani S, Vasantha VS, Chang YT. A new alternative adsorbent for the removal of cationic dyes from aqueous solution. Arab. J. Chem. 2016;9:466-474.

11. Liang CZ, Sun SP, Li FY, Ong YK, Chung TS. Treatment of highly concentrated wastewater containing multiple synthetic dyes by a combined process of coagulation/ flocculation and nanofiltration. J. Membr. Sci. 2014;469:306-315.

12. Sarala P, Venkatesha TV. Electrochemical degradation of p-aminobenzoic acid $\beta$-naphthol azo dye in alkaline solution. J. Environ. Chem. Ecotoxicol. 2006;4:116-123.

13. Chun HN, Chun-Chieh F, Ruey-Shin J. Degradation of methylene blue and methyl orange by palladium-doped $\mathrm{TiO}_{2}$ photocatalysis for water reuse: Efficiency and degradation pathways. J. Clean. Prod. 2018;202:413-427.

14. Vinodgopal K, Julie P. Hydroxyl radical-mediated advanced oxidation processes for textile dyes: a comparison of the radiolytic and sonolytic degradation of the monoazo dye Acid Orange 7. Res. Chem. Intermed. 2003;29:307-316.

15. Nurhidayatullaili MJ, Samira B, Sharifah BAH. Recent advances in heterogeneous photocatalytic decolorization of synthetic dyes. Sci. World J. 2014:1-25.

16. Collin GJ, Yun-Hin TY, Gianluca LP, Kogularama S, Kye SQ. Photocatalytic degradation of cationic dye simulated wastewater using four radiation sources, UVA, UVB, UVC and solar lamp of identical power output. Desalin. Water Treat. 2015:1-12.

17. Peternel IT, Koprivanac N, Bozic AML, Kusic HM. Comparative study of $\mathrm{UV} / \mathrm{TiO}_{2}, \mathrm{UV} / \mathrm{ZnO}$ and photo-Fenton processes for the organic reactive dye degradation in aqueous solution. $J$. Hazard. Mater. 2007;148:477-484.
18. Ananpattarachai J, Supapan S, Puangrat K. Formation of hydroxyl radicals and kinetic study of 2-chlorophenol photocatalytic oxidation using C-doped $\mathrm{TiO}_{2}$, N-doped $\mathrm{TiO}_{2}$, and C,N Co-doped $\mathrm{TiO}_{2}$ under visible light. Environ. Sci. Pollut. Res. 2015;23: 3884-3896.

19. Selvam K, Balachandran S, Velmurugan R, Swaminathan M. Mesoporous nitrogen doped nano titania - A green photocatalyst for the effective reductive cleavage of azoxybenzenes to amines or 2-phenyl indazoles in methanol. Appl. Catal. A: General 2012;413-414:213-222.

20. Thayyath SA, Divya PL, Nima J, Sandeep S. Synthesis and evaluation of Iron-doped titania/silane based hydrogel for the adsorptional photocatalytic degradation of Victoria blue under visible light. J. Colloid. Interf. Sci. 2014;434:48-58.

21. Jiasong Z, Jinrong X, Qingyao W. Nitrogen and vanadium Co-doped $\mathrm{TiO}_{2}$ mesosponge layers forenhancement in visible photocatalytic activity. Appl. Surf. Sci. 2014;315:131-137.

22. Saraschandra N, Thejaswini TVL, Prabhakaran D, et al. Enhanced photo-catalytic activity of Sr and Ag co-doped $\mathrm{TiO}_{2}$ nanoparticles for the degradation of Direct Green-6 and Reactive Blue-160 under UV \& visible light. Spectrochim. Acta Part A: Mol. Biomol. Spectrosc. 2015;149:571-579.

23. Safni Reza AP, Upita S, Diana VW. Photodegradation of Orange F3R Dyes: Effect of Light Sources and the Addition of C-N-Codoped $\mathrm{TiO}_{2}$ Catalyst. Der pharma chemica 2017;9:1-5.

24. Safni, Diana VW, Puti SK, Reza AP. Degradation of yellow-GCN by photolysis with UV-light and irradiation using C-N-codoped $\mathrm{TiO}_{2}$ catalyst. J. Chem. Pharm. Res. 2015;7:306-311.

25. Qing C, Diana V, Shi Y, Dai WL, Tuti M, Timothy T. Enhanced photocatalytic activity of C-N-codoped $\mathrm{TiO}_{2}$ film prepared via anorganic-free approach. J. Hazard. Mater. 2011;188:172-180.

26. Diana VW, Dytta F, Safni. C-N-codoped $\mathrm{TiO}_{2}$ synthesis by using peroxo sol gel method for photocatalytic reduction of $\mathrm{Cr}(\mathrm{VI})$. J. Pure Appl. Chem. Res. 2018;7:25-31.

27. Sun J, Qiao L, Sun S, Wang G. Photocatalytic degradation of Orange $\mathrm{G}$ on nitrogen-doped $\mathrm{TiO}_{2}$ catalysts under visible light and sunlight irradiation. J. Hazard. Mater. 2007;155:312-319.

28. Azami MS, Nawawi WI, Ishak MAM, Ismail K, Ahmad Z, Ali HJ. Carbon Nitrogen Co-Doped P25: Parameter Study on Photodegradation of Reactive Red 4. In: MATEC Web of Conferences. 2016;47:5-18.

29. Liu HJ, Liu GG, Xie GH, Zhang ML, Hou ZH, ZW He. Gd ${ }^{3+}$, N-codoped tri-titanate nanotubes: Preparation, characterization and photocatalytic activity. Appl. Surf. Sci. 2010;257:3728-3732.

30. Thillai SN, Molly T, Kalithasan N, Hari CB, Rajesh JT. Study on UV-LED/ $\mathrm{TiO}_{2}$ process for degradation of Rhodamine B dye. Chem. Eng. J. 2011;169:126-134.

31. Salvador P. On the nature of photogenerated radicals species active in the oxidative degradation of dissolved pollutants with $\mathrm{TiO}_{2}$ aqueous suspension: a revision in the light of the electronic structure of adsorbed water. J. Phys. Chem. C. 2007;111: 17038-17043.

32. Singh J, Chang YY, Koduru JR, Yang JK. Potential degradation of methylene blue $(\mathrm{MB})$ by nano-metallic particles: A kinetic study and possible mechanism of $\mathrm{MB}$ degradation. Environ. Eng. Res. 2018;23:1-9.

33. Son H.S, Ko G.P, Zoh KD. Kinetics and menchanism of photolysis 
and $\mathrm{TiO}_{2}$ photocatalysis of triclosan. J. Hazard. Mater. 2009;166:954-960.

34. Xiaoping W, Teik-Thye L. Solvothermal synthesis of C-N codoped $\mathrm{TiO}_{2}$ and photocatalytic evaluation for bisphenol A degradation using a visible-light irradiated LED photoreactor. Appl. Catal. B: Environ. 2010;100:355-364.

35. Haithem BH, Zina MB, Galvez ME, Costa PD. Photocatalytic degradation of methyl green dye in aqueous solution over natural clay-supported $\mathrm{ZnO}-\mathrm{TiO}_{2}$ Catal. J. Photochem. Photobiol. A:
Chem. 2016;315:25-33.

36. Liu JW, Han R, Zhao Y, et al. Enhanced photoactivity of V-N codoped $\mathrm{TiO}_{2}$ derived from a two-step hydrothermal pro-cedure for the degradation of PCP-Na under visible light irradiation. J. Phys. Chem. C 2011;115:4507-4515.

37. Son HS, Lee SJ, Cho IH, Zoh KD. Kinetics and mechanism of TNT degradation in $\mathrm{TiO}_{2}$ photocatalysis. Chemosphere 2004;57:309-317. 